\title{
Book Review - Buchbesprechung - Livre nouveau
}

W. Dick: Respiratorischer Flüssigkeits- und Wärmeverlust des Säuglings und Klein-kindes bei künstlicher Beatmung. Springer, Berlin/Heidelberg/Ne.v York 1972. VIII + 69 S., 24 Abb.; DM 32.-/US-S 10.20.

Es handelt sich um eine Untersuchung über Wärme- und Wasserverlust bei künst licher Beatmung von Säuglingen und Kleinkindern. Der Autor hat verschiedene Korrelationen, z.B. zum Beatmungszeitvolumen, Alter, Gewicht, Körperoberfläche usw., untersucht, ebenso den Einfluss eines Wärme-Feuchte-Austauschers sowie die Wirkung eines Ultraschallverneblers. Für die Anwendung des letzteren gibt er detaillierte Vorschriften. Die Abhandlung ist hauptsächlich für Ärzte, die sich mit der Beatmung von Säuglingen und Kleinkindern befassen, interessant. M. Vest 